\title{
Icons and icons
}

\author{
Decision support using coaching and expert systems \\ Jolán Velencei - Zoltán Baracskai - Viktor Dörfler
}

The authors of this paper spent over three decades on average working with, for and on business decision takers, typically top executives. We have been working with them in different parts of their organisations, for them in a variety of advisory roles, and on them in various research projects trying to understand the process of decision making and decision taking. In this paper we reflect on our consultancy and research experience involving decision takers in order to conceptualize a distinction between two types of decisions with regards to the way of supporting them. Therefore, purpose of the study could be described as an attempt of a minimalist decision typology (involving only two types) where the two decision types are achieved by their characteristics and then we argue that two different approaches to decision support can be useful for the two types of decisions. This paper qualifies as a conceptual one informed by underlying empirical studies. These empirical underpinnings comprise of three types: (1) designed as qualitative empirical research projects, involving participant observations, interviews, focus groups, and knowledge modelling using knowledge-based expert systems, (2) consultancy carried out through executive coaching and knowledge engineering, and (3) a mix of the previous two in action research projects. We reflect on these experiences in this paper drawing speculative conclusions using retrospective sensemaking - therefore the resulting model is a conceptual one and we offer it for debate and potential conceptual for forthcoming research projects for the academic audience interested in decision making. Additionally, the model can also be useful for practicing executives, in deciding what kind of decision support to seek for the particular decision at hand, as well as for consultants to figure out what type of decision support to offer.

The super-large decisions that may redefine the organisation we call Icons (with capital ' $I$ '), referring to the notion of Iconic. These decisions require exceptionally high degree of competence. The second group consists of those insignificant decisions that do not require any substantial degree of competence; we call these as icons (with lower case ' $i$ ') referring to the icons that we need to click or touch in order to run an app on our computers, tablets, smartphones or wearables. It is perhaps obvious that Icons need very different types of decision support than icons. To get a better understanding of this, we need to look at the dominant knowledge type used in the decision situations. We distinguish three types of knowledge: facts, skills, and intuition (Figure 1). Facts are not of primary focus in most decision situations and these are pre-processed and provided by ERP (Enterprise Resource Planning) systems. Skills play a significant role in the professional lives of practicing managers, but they actually need one single skill: communication. Good managers are typically good communicators. Therefore, the focus in the case of both Icons and icons is intuition. 


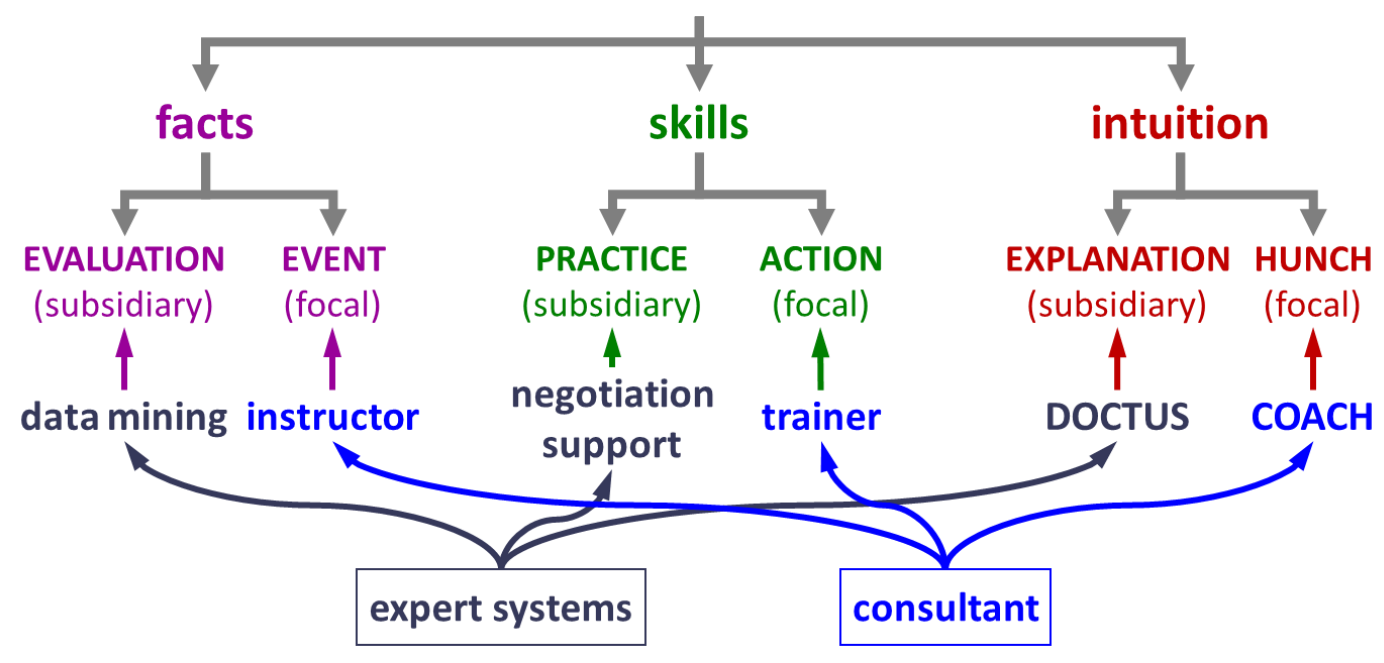

In Icons the dominant knowledge is focal intuition, which we call hunch. The dominant knowledge in icons is subsidiary intuition, which we call explanation. Thus, Icons call for a coach who can help decision takers clarify their expectations, while icons need knowledgebased expert systems which can help develop organisational routines. 